\title{
Primeiro registro documentado do gavião-belo, Busarellus nigricollis (Latham, 1790) (Aves: Accipitridae), para o Estado de Santa Catarina, Brasil
}

\author{
Felipe Zilio \\ PPG em Biologia Animal, Departamento de Zoologia \\ Instituto de Biociências, Universidade Federal do Rio Grande do Sul \\ Avenida Getúlio Vargas, 888/404 - CEP 90150-002 - Porto Alegre - RS \\ fzilio@msn.com
}

Submetido em 18/11/2008

Aceito em 12/03/2009

\section{Resumo}

Embora o gavião-belo possua ampla área de ocorrência no Brasil, os registros são escassos nos limites meridionais de sua distribuição. Em Santa Catarina, sua presença foi registrada pela primeira vez apenas em 1999. Em abril de 2007, um jovem de gavião-belo foi visto e fotografado no sul de Santa Catarina, constituindo o primeiro registro documentado da espécie para o estado.

Unitermos: Busarellus nigricollis, registro documentado, Santa Catarina

\section{Abstract}

First documented record of Black-collared Hawk Busarellus nigricollis (Latham, 1790) for the state of Santa Catarina, Brazil. The Black-collared Hawk has a wide distribution in Brazil, but records are scarce in the southern limits of its range. In the state of Santa Catarina its occurrence was reported for the first time in 1999. In April 2007, a juvenile was seen and photographed in southern Santa Catarina. This is the first documented record of the species for the state.

Key words: Busarellus nigricollis, documented record, Santa Catarina

Busarellus nigricollis (gavião-belo) é uma espécie cuja distribuição abrange uma grande área da região Neotropical $\left(26^{\circ} \mathrm{N}\right.$ até $\left.34^{\circ} \mathrm{S}\right)$, ocorrendo do México ao Uruguai, e em praticamente todo o território brasileiro (Sick, 1997; Ferguson-Lees e Christie, 2001). Habita uma ampla gama de ambientes aquáticos, como mangues, pântanos, banhados, margens alagadas de rios, lagoas, arrozais, usualmente em altitudes inferiores a $500 \mathrm{~m}$, podendo, porém, ser encontrado localmente em altitudes de até 1.500m (Ferguson-Lees e Christie,
2001). Sua dieta consiste principalmente de peixes, mas anfíbios, filhotes de aves aquáticas, grandes insetos, moluscos e, eventualmente, pequenas aves, mamíferos e répteis, também constituem itens consumidos pela espécie (Ferguson-Lees e Christie, 2001).

Apesar de sua ampla distribuição no Brasil, são conhecidos poucos registros de $B$. nigricollis no extremo sul do país, próximo ao limite meridional de sua distribuição. No Rio Grande do Sul, B. nigricollis 
encontra-se ameaçado de extinção (vulnerável; Marques et al., 2002) e provavelmente está em declínio (Bencke et al., 2003), sendo conhecidos registros da espécie em apenas quatro localidades, do oeste ao leste do estado ao longo da Depressão Central (Bencke et al., 2003; Accordi e Barcellos, 2006). Em Santa Catarina a espécie foi registrada pela primeira vez somente em 1999, em Santa Cecília, na região do planalto catarinense (Amaral, 2002).

No dia 14 de abril de 2007, durante atividade de monitoramento de fauna na Usina Hidrelétrica (UHE) Barra Grande, período de pós-enchimento do reservatório, foi visualizado e fotografado um jovem de $B$. nigricollis (Figura 1) em uma área pertencente à Fazenda Florestal Gateados Ltda., no município de Campo Belo do Sul - SC (28 $1^{\prime}$ '55"S; 5051'5”'W; altitude $c a .900 \mathrm{~m})$. O indivíduo foi visualizado às $11 \mathrm{~h} 10 \mathrm{~min}$ em vôo e pousou em um Pinus sp. nas proximidades de um pequeno açude. Poucos minutos depois voou até um Eucalyptus sp., onde permaneceu por um período inferior a $10 \mathrm{~min}$, em atividade de forrageio (pousado observando o açude, movendo a cabeça para os lados acompanhando os movimentos na água), até alçar vôo e desaparecer. Como o único registro prévio de $B$. nigricollis para Santa Catarina é o de Amaral (2002), o presente registro constitui-se no segundo da espécie para o estado, sendo o primeiro documentado.

A escassez de registros nos estados do sul do Brasil torna difícil avaliar a possível influência da formação do reservatório da UHE Barra Grande sobre a distribuição da espécie. A alteração recente nas características dos rios da região, gerada pela construção de barramentos (e.g. UHE Machadinho, UHE Itá, UHE Campos Novos), associada à existência de olhos d'água artificiais de diferentes portes (e.g. açudes), pode ter influenciado no deslocamento de indivíduos para o planalto catarinense, seguindo o fluxo dos rios Uruguai e Pelotas e seus afluentes. Contudo, apesar de B. nigricollis não ter sido registrado na área no período anterior à formação do reservatório (dados não publicados), é possível que a espécie já ocorresse na região, não tendo sido registrada antes devido à sua raridade.

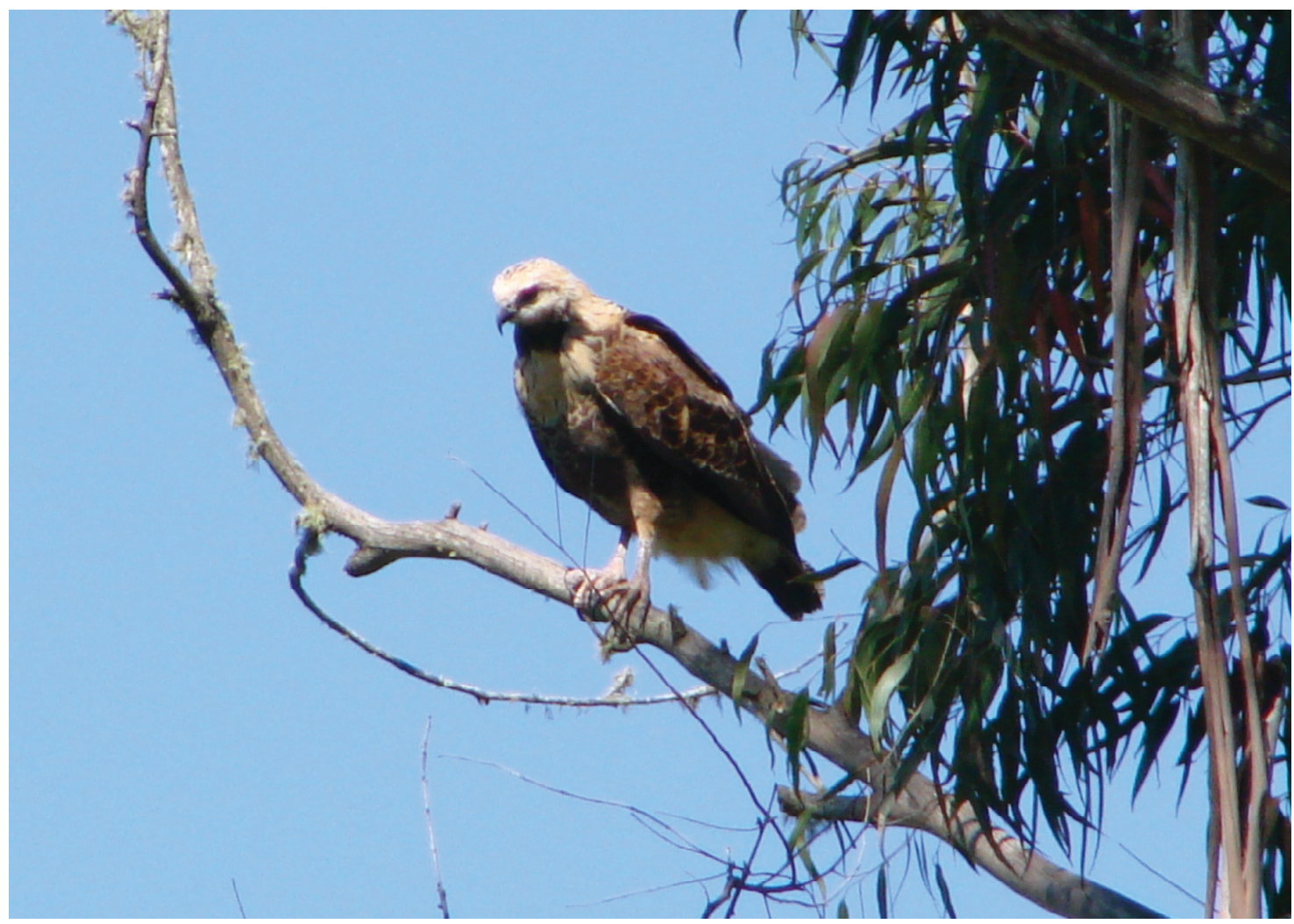

FIGURA 1: Jovem de Busarellus nigricollis (gavião-belo) registrado nas proximidades de um açude no município de Campo Belo do Sul, Santa Catarina, Brasil, em 14 de abril de 2007. 
Os registros de B. nigricollis ocorridos em Santa Catarina e no Rio Grande do Sul são dispersos o que sugere que a espécie não ocorra regularmente na região. Além disso, movimentos migratórios e de dispersão podem estar envolvidos. Sabe-se que $B$. nigricollis, embora predominantemente sedentário, realiza movimentos locais em resposta a variações nos recursos hídricos (Ferguson-Lees e Christie, 2001), pouco se sabendo sobre a dispersão de juvenis. É provável que o indivíduo observado tenha sido um vagante, por tratarse de um jovem e dada a inexistência de evidências de reprodução da espécie em Santa Catarina e no Rio Grande do Sul. Nesse caso, a continuidade dos trabalhos de monitoramento de fauna na área de influência da UHE Barra Grande pode contribuir para o conhecimento do status de ocorrência da espécie na região.

\section{Agradecimentos}

A todos os colegas pesquisadores e funcionários da UFRGS e auxiliares de campo atuantes no monitoramento de fauna da UHE Barra Grande pela colaboração e auxílio em campo, sem os quais não apenas este registro, mas muito do trabalho que vem sendo desenvolvido na região não seria possível. Aos colegas agradeço também pelo auxílio, direto ou indireto, para a elaboração desta nota, a Leonardo Zilio pela colaboração na finalização do abstract e aos dois revisores anônimos pelas substanciais contribuições. Também agradeço à Direção da BAESA S.A. pela autorização para a divulgação dos dados aqui apresentados.

\section{Referências}

Accordi, I. A.; Barcellos, A. 2006. Composição da avifauna de oito áreas úmidas da Bacia Hidrográfica do Lago Guaíba, Rio Grande do Sul. Revista Brasileira de Ornitologia, 14 (2): 101-115.

Amaral, C. 2002. Ocorrência do gavião-belo Busarellus nigricollis no estado de Santa Catarina. Ararajuba, 10 (2): 245.

Bencke, G. A.; Fontana, C. S.; Dias, R. A., Maurício, G. N.; Mähler Jr, J. K. F. 2003. Aves. In: Fontana, C. S.; Bencke, G. A. \& Reis, R. E. (Orgs). Livro vermelho da fauna ameaçada de extinção no Rio Grande do Sul. EDIPUCRS, Porto Alegre, Brasil, p.189 $-477$.

Fegurson-Lees, J.; Christie, D. A. 2001. Raptors of the world. Houghton Mifflin Company, New York, USA, 992pp.

Marques, A. A. B.; Fontana, C. S., Vélez, E.; Bencke, G. A.; Schneider, M.; Reis, R. E. 2002. Lista de referência da fauna ameaçada de extinção no Rio Grande do Sul. Decreto ${ }^{\circ} 41.672$, de 10 junho de 2002. FZB/MCT-PUCRS/PANGEA, Porto Alegre, Brasil, 52pp (Publicações Avulsas FZB, 11).

Sick, H. 1997. Ornitologia Brasileira. $2^{\text {a }}$ ed. Nova Fronteira, Rio de Janeiro, Brasil, 862pp. 